\title{
CORRESPONDENCE
}

\section{THE USE OF COLCHICINE IN GOUT*}

To the Editors, Annals of the Rheumatic Diseases.

SIRS,

The article "Intravenous Colchicine in the Management of Gouty Arthritis" by W. Graham and J. B. Roberts, which appeared in your issue of March, 1953 (1), states that:

In June, 1949, a French preparation for parenteral administration became available to us, and treatment of a series of patients was begun. At that time no references were found in the English literature to the use of colchicine intravenously in the treatment of gout ...

Readers should be referred to the paper entitled "Gout-a Prevalent Arthritic Disease", which was read by Solomon and Stecher, of Cleveland, Ohio, at the Eastern Sectional Meeting of the American Congress of Physical Therapy on April 5, 1941 (2). In the discussion which followed this valuable paper, Prof. Russell L. Cecil stated inter alia:

I do not know of any more dramatic treatment than to give a patient suffering from acute gout an intravenous injection of colchicine ...

Prof. Cecil later informed me that he was using ampoules of sodium salicylate and iodine with Colchicine No. 1, manufactured by Eli Lilly and Co., of Indianapolis, U.S.A., and the South African Lilly representative supplied me with this preparation early in 1942.

* It is regretted that so long a delay has occurred in the publication of this letter.
My personal experience with intravenous colchicine, appeared in April, 1949, in a paper entitled "The Gouty Diathesis" (3), in which I stated that the first dose is usually $1 \mathrm{mg}$. and the following doses only $0.5 \mathrm{mg}$. It is therefore inaccurate to state that there was "no reference in the English literature to the use of colchicine intravenously before June, 1949".

Because much smaller doses than those used by Graham and Roberts have given such dramatic results and because of the cumulative effect of colchicine, I am strongly against the intravenous administration of the heroic 3-mg. dose advocated by these authors. I have never seen any "irritant effect on the gastro-intestinal tract", although I have now given about 5,000 intravenous injections containing colchicine to patients of different ages and sexes. I have never as yet exceeded the $1 \mathrm{mg}$. and $0.5 \mathrm{mg}$. doses, however, even in patients whose tolerance of colchicine was well known to me.

Yours faithfully,

76 Harrow Road,

\section{NATHAN FINN}

Yeoville,

Johannesburg, Union of South Africa.

May 12, 1953.

\section{REFERENCES} (1) Graham, W., and Roberts, J. B. (1953). Annals of the Rheumatic
Diseases, 12, 16.

(2) Solomon, W. M., and Stecher, R. M. (1941). Arch. phys. Med., 22, 462.

(3) Finn, N. (1949). S. Afr. med. J., 23, 276 (issued April, 1949).

\section{BOOK REVIEW}

VIII Congreso Internacional de Enfermedades Reumaticás.

1953. Pp. 114. Rev. esp. Reum., vol. 5, no. 4, p. 153.

Sociedad Española de Reumatismo, Barcelona. (60 pesetas).

This review covers the papers given at various sessions of the Congress held at Geneva in 1953. The subjects dealt with, in the main, were: connective tissue and rheumatism, steroid hormones, the surgery of the hipjoint, rehabilitation of chronic patients, and the use of Butazolidin; a final session was devoted to a variety of subjects. Short summaries are given of each paper presented.

It is quite obvious that much research has gravitated recently to studying the structure and biochemistry of connective tissue. These problems are extremely complicated and various papers were given to try to elucidate the factors governing the growth and pathology of collagen, elastic tissue, etc. This work, in its initial stages, is mostly grounded in theory but may well bear considerable fruit in the near future.

With regard to the hormones, P. S. Hench stresses the importance of assessing each patient individually. Of his "systems" the one of small doses over long periods seems to be preferred; he still uses gold in suitable cases. E. G. L. Bywaters and others have found little difference in the results of treating rheumatic fever with ACTH, cortisone, or salicylate. Most authors agree that small intra-articular doses of hormone are decidedly beneficial, especially in the knee-joint. Hormones are thought to be of little value in degenerative arthritis.

The reports on Butazolidin were very favourable. Some consider that the remissions last longer than those with ACTH. The numerous complications should not preclude its use. It is effective in gout but especially so in rheumatoid arthritis and ankylosing spondylitis. Modern opinion is that it does not act by stimulating the pituitaryadrenal mechanism.

Plastic operations on the hip-joint seem to produce good results in 60-80 per cent. of cases; R. J. Judet considers severe pain one of the main indications for operation, but believes in persevering with conservative measures prior to surgery.

The papers on rehabilitation were along the usual lines. 